\title{
Ovomucin-Food Protein Conjugates Prepared through the Transglutaminase Reaction
}

\author{
Akio Kato, Takayuki Wada, Kunihiko Kobayashi, \\ Katsuya Seguro* and Masao Motoki* \\ Department of Agricultural Chemistry, Yamaguchi University, Yamaguchi 753, Japan \\ * Central Research Laboratories, Ajinomoto Co., Inc., Kawasaki 210, Japan
}

Received October 5, 1990

\begin{abstract}
Ovomucin-protein conjugates were prepared to develop a new kind of functional glycoprotein-protein conjugates. Soluble reduced ovomucin was self-associated by transglutaminase and the reactant had better foaming and emulsifying properties than untreated ovomucin. The conjugation of ovomucin with casein or soy protein was also attempted by transglutaminase. Ovomucin-11S globulin and ovomucin- $\alpha_{\mathrm{S} 1}$-casein conjugates were formed by cross-linking between ovomucin and $11 \mathrm{~S}$ globulin or $\alpha_{\mathrm{S}_{1}}$-casein. The molecular weight of these conjugates were larger than that of ovomucin self-associated with transglutaminase. Ovomucin-11S globulin conjugate showed marked increases in the foaming properties, because of the high molecular weight of the conjugate. On the other hand, ovomucin- $\alpha_{S_{1}}$-casein conjugate had significant increases in the emulsifying properties, probably due to the increase in the hydrophobic( $\alpha_{\mathrm{S} 1}$-casein)-hydrophilic(ovomucin) balance.
\end{abstract}

Recently, protein-macromolecule conjugates, a new field in protein research, has attracted considerable attention. Proteins are generally unstable to heating, proteolytic attack, and organic solvents. However, proteins may gain resistance to them by conjugation with macromolecules such as polysaccharides and synthetic polymers. In addition, these bioconjugation may shed light on the feasibility of new functional properties. We found that soluble protein-dextran conjugates had excellent emulsifying properties, superior to commercial emulsifiers. ${ }^{1)}$ The protein-dextran conjugates were prepared by coupling proteins to $\mathrm{CNBr}$-activated dextran ${ }^{1)}$ or by linking proteins with dextran through the naturallyoccurring Maillard reaction. ${ }^{2)}$

Enzymatic conjugation of proteins with polysaccharides is favorable to further industrial applications. In this study, we tried to develop protein-polysaccharide conjugates using transglutaminase. This enzyme catalyzes the acyltransfer reaction between an amide group in a protein-bound glutamine and an $\varepsilon$-amino group in a protein-bound lysine side chain, and cross-links between protein molecules. Chemi- cal modifications are required to introduce active amino groups in polysaccharides. To overcome this difficulty, a highly glycosylated glycoprotein, ovomucin, has been used in this paper, instead of polysaccharide. Ovomucin is a heat-stable, functional glycoprotein with excellent foaming properties and good emulsifying properties. Therefore, the conjugation of proteins with ovomucin is a promising approach to new functional proteins.

\section{Materials and Methods}

Materials. Ovomucin was prepared from fresh chicken egg white by the method described in a previous paper. ${ }^{3)}$ $\alpha_{\mathrm{S1}}$-Casein was prepared from fresh milk by the method of Zittle and Custer. ${ }^{4)} 11 \mathrm{~S}$ globulin was prepared from soybean by the method of Thanh et al. ${ }^{5)}$ Transglutaminase (derived from Streptoverticillium $s p$.) was supplied by Ajinomoto Co., Inc.

Preparation of reduced ovomucin. Ovomucin was suspended in $0.1 \mathrm{M}$ phosphate buffer, $\mathrm{pH} 7.0$, and then reduced by the addition of $0.1 \%$ mercaptoethanol. The ovomucin solution thus obtained was dialyzed against the same phosphate buffer.

Acetylation of $\alpha_{\mathrm{S} 1}$-casein and $11 S$ globulin. To acetylate 
$\alpha_{\mathrm{S} 1}$-casein and $11 \mathrm{~S}$ globulin, protein $(500 \mathrm{mg})$ was dissolved in $20 \mathrm{ml}$ of $6.6 \mathrm{M}$ urea mixed with $2 \mathrm{M}$ Tris- $\mathrm{HCl}$ buffer, $\mathrm{pH}$ 7.6. Acetic anhydride was added in $80-\mu 1$ increments up to a total of $1.5 \mathrm{ml}$ over a $2-\mathrm{hr}$ period when the mixture was dialyzed against deionized water and then lyophilized.

Transglutaminase reaction. To $10 \mathrm{ml}$ of $0.1 \%$ ovomucin solution in $0.1 \mathrm{M}$ phosphate buffer, $\mathrm{pH} 7.0$, were added $0.1 \mathrm{ml}$ of $0.1 \%$ transglutaminase solution. The mixture was incubated at $55^{\circ} \mathrm{C}$ for $60 \mathrm{~min}$. The enzymatic reaction was stopped by the addition of $0.1 \mathrm{ml}$ of $0.1 \% \mathrm{~N}$ ethylmaleimide. The reaction mixture was dialyzed against deionized water and then lyophilized. When ovomucinprotein conjugates were prepared, an equal volume of $0.1 \%$ ovomucin solution was added to $0.1 \%$ protein solutions and then was reacted under the same conditions as described above.

SDS-slab polyacrylamide gel electrophoresis. SDS-slab polyacrylamide gel electrophoresis was done by the method of Laemmli ${ }^{6}$ using $5 \%$ acrylamide separating gel, and $3 \%$ stacking gel containing $0.1 \%$ SDS. Protein samples $(20 \mu \mathrm{l}$, $0.1 \%$ ), were prepared in Tris glycine buffer, $\mathrm{pH} 8.8$, containing $1 \%$ SDS and $1 \%$ mercaptoethanol. Electrophoresis was done at constant current of $10 \mathrm{~mA}$ for $5 \mathrm{hr}$ in electrophoretic Tris-glycine buffer containing $0.1 \%$ SDS. The gel sheets were stained for proteins and carbohydrates with Coomassie blue G-250 and fuchsine, respectively.

Measurement of the molecular weight of ovomucin-protein conjugate. One-tenth percent ovomucin-protein conjugate solution in $0.1 \mathrm{M}$ sodium phosphate buffer $(\mathrm{pH} 7.0$ ) containing $0.1 \%$ SDS was put on a high performance gel chromatography system, using a TSK gel G3000SW column (Toyo Soda Co., $0.75 \times 60 \mathrm{~cm}$ ) at a flow rate of $0.3 \mathrm{ml} / \mathrm{min}$. Effluent from the column was monitored with a low-angle laser light scattering photometer (LS-8, Toyo Soda Co.) and then with a precision differencial refractometer (RI-8, Toyo Soda Co.). The molecular weight of ovomucin-protein conjugate was estimated from the ratio of total area in the peak of the low-angle laser light scattering photometer (LS) to that of the refractometer (RI) by the method of Takagi and Hizukuri. ${ }^{7)}$

Measurement of emulsifying properties. Emulsifying properties were measured by the method of Pearce and Kinsella. ${ }^{8)}$ To prepare emulsions, $1.0 \mathrm{ml}$ of corn oil and $3 \mathrm{ml}$ of $0.1 \%$ protein solution in $0.1 \mathrm{M}$ phosphate buffer, $\mathrm{pH} 7.0$, were shaken together and homogenized in an Ultra Turrax (Hansen \& Co., West Germany) at 12,000 rpm for $1 \mathrm{~min}$ at $20^{\circ} \mathrm{C}$. Fifty $\mu \mathrm{l}$ of emulsion was taken from the bottom of the container at different times and diluted with $5 \mathrm{ml}$ of $0.1 \%$ sodium dodecyl sulfate solution. The absorbance of diluted emulsion was then measured at $500 \mathrm{~nm}$. The emulsifying activity was calculated from the absorbance measured immediately after emulsion forma- tion. The emulsion stability was estimated by measuring the half-time of the turbidity of emulsion.

Measurement of foaming properties. The foaming properties of proteins were measured by the electric conductivity of foams when air was introduced into $5 \mathrm{ml}$ of a $0.1 \%$ protein solution in $0.1 \mathrm{~m}$ phosphate buffer, $\mathrm{pH}$ 7.0 , in a glass filter (G-4) at a constant flow rate, $90 \mathrm{~cm}^{3} / \mathrm{min}$, for $15 \mathrm{sec} .^{9)}$

\section{Results and Discussion}

Transglutaminase has a stringent sequence specificity requirement for the acceptor site but can recognize a wide variety of alkylamines as donors. ${ }^{10)}$ Therefore, the versatility of ovomucin as a substrate for transglutaminase was investigated. Figure 1 shows the electrophoretic patterns of ovomucin and transglutaminasetreated ovomucin. As can be seen from electrophoretic patterns, ovomucin consists of carbohydrate-rich (slow mobility) and poor (fast mobility) components. The former is

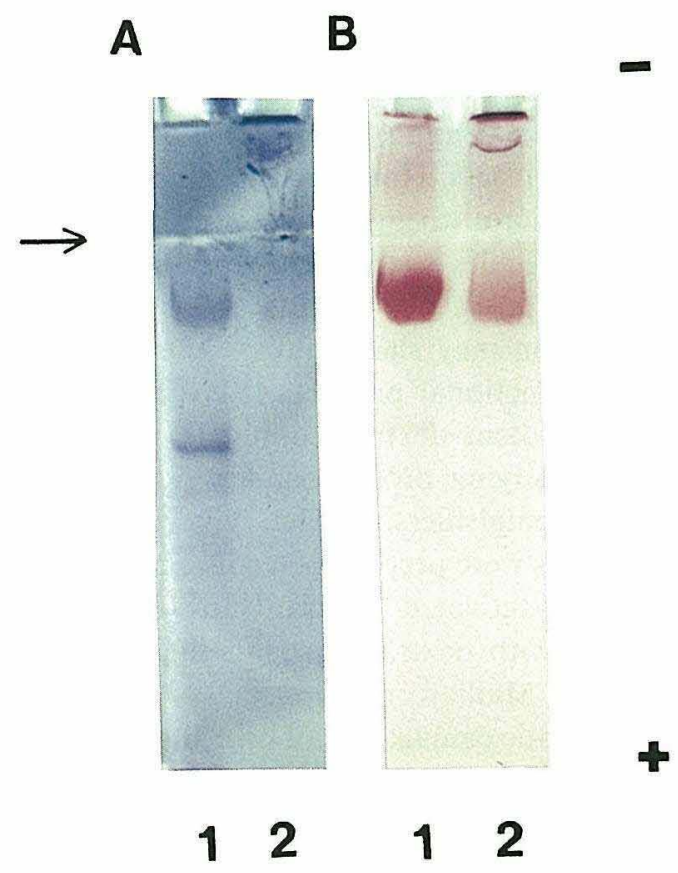

Fig. 1. Electrophoretic Patterns of Ovomucin and Transglutaminase-treated Ovomucin.

A, protein stain; B, carbohydrate stain. Lane 1, ovomucin; Lane 2, transglutaminase-treated ovomucin. Arrow indicates the position of the boundary between stacking (upper) and separating (under) gels. 
A

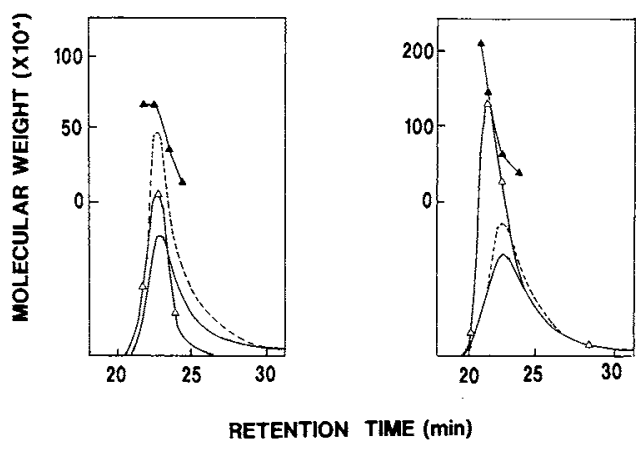

Fig. 2. Elution Patterns of Ovomucin and Transglutaminase-treated Ovomucin on a TSK Gel G3000SW Column Obtained with a Low-angle Laser Light Scattering Photometer $(-\triangle-)$, a Precision Differential Refractometer (-), and a UV Detector (----).

A, ovomucin; B, transglutaminase-treated ovomucin. molecular weight.

named $\beta$-ovomucin and the latter is named $\alpha$-ovomucin. ${ }^{11)}$ Both ovomucins were converted to polymerized forms, which were unable to enter the stacking gel in electrophoresis, by transglutaminase treatment. This suggests that ovomucins react with transglutaminase to cross-link between the molecules.

The molecular weights of ovomucin and transglutaminase-treated ovomucin were compared to clarify the mode of cross-linkage. The elution curves in Fig. 2 make it possible to estimate the molecular weight of the fraction eluted at a particular retention time and its relative population. ${ }^{7)}$ As shown in Fig. 2, the molecular weight of untreated ovomucin was distributed from 200,000 (correspond to $\alpha$-ovomucin) to 700,000 (correspond to $\beta$ ovomucin), while the molecular weight of transglutaminase-treated ovomucin was 200,000 to $2,000,000$. This suggests that the degree of polymerization of ovomucin subunits by transglutaminase is oligomeric in the condition used here.

The foaming properties of ovomucin were improved by transglutaminase treatment (Fig. 3 ). Ovomucin is an excellent foaming protein. The foaming properties of ovomucin were further improved by transglutaminase treatment, reflecting the strengthening of the foam

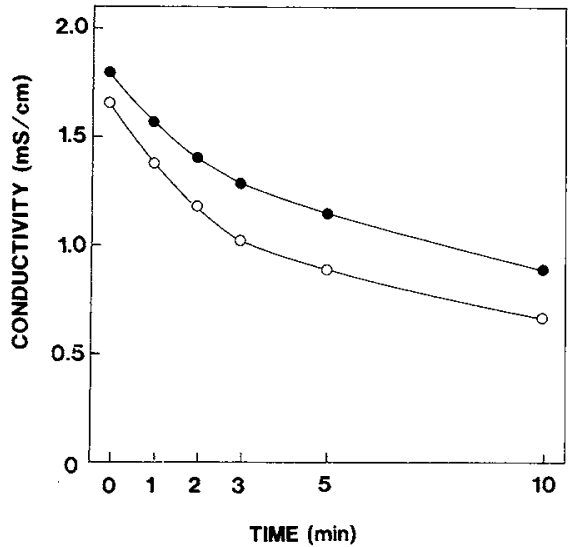

Fig. 3. Foaming Properties of Ovomucin and Transglutaminase-treated Ovomucin.

O, ovomucin; 0 , transglutaminase-treated ovomucin

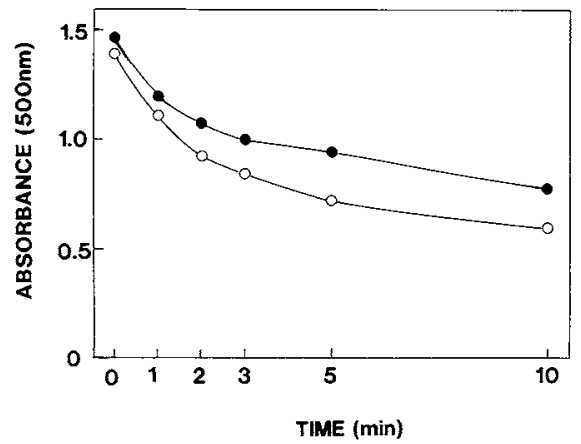

Fig. 4. Emulsifying Properties of Ovomucin and Transglutaminase-treated Ovomucin.

$\bigcirc$, ovomucin; $\bigcirc$, transglutaminase-treated ovomucin.

films due to the polymerization.

The emulsifying properties of ovomucin were also increased by transglutaminase (Fig. 4). We have reported that the emulsifying property of native polymerized ovomucin is lower than that of depolymerized ovomucin (reduced form). Therefore, the ovomucin polymerized by transglutaminase may be more amphiphilic than native polymerized ovomucin.

The conjugation of ovomucin with $\alpha_{\mathrm{S} 1}$-casein or $11 \mathrm{~S}$ globulin was attempted by transglutaminase. Casein and soy protein are known as substrates of transglutaminase. Since these proteins are self-associated by transglutaminase, amino groups in these proteins are acetylated before the transglutaminase reaction 
A

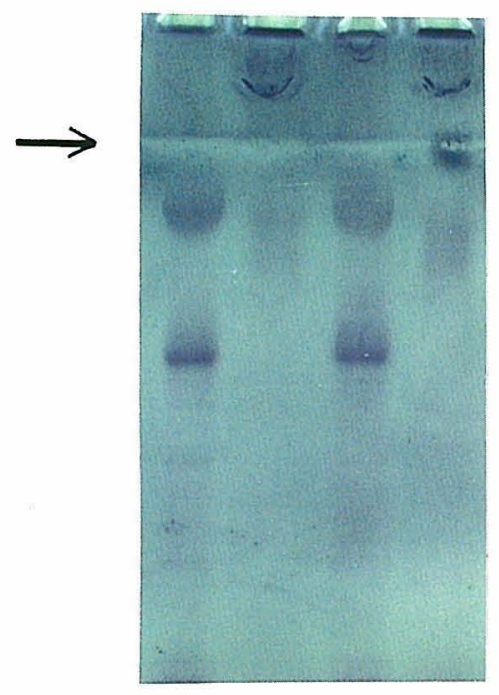

$\begin{array}{llll}1 & 2 & 3 & 4\end{array}$
B
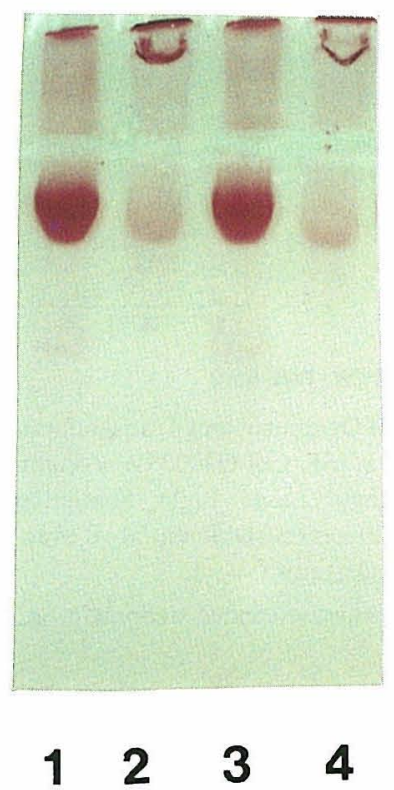

Fig. 5. Electrophoretic Patterns of Ovomucin- $\alpha_{\mathrm{S} 1}$-Casein and Ovomucin-11S Globulin Conjugates.

A, protein stain; B, carbohydrate stain. Lane 1, ovomucin $+\alpha_{\mathrm{S} 1}$-casein; Lane 2 , ovomucin $+\alpha_{\mathrm{S} 1}$-casein + transglutaminase; Lane 3, ovomucin $+11 \mathrm{~S}$ globulin; Lane 4, ovomucin $+11 \mathrm{~S}$ globulin + transglutaminase. Arrow indicates the position of the boundary between stacking (upper) and separating (under) gels.

to prevent the self-association. The acetylated $\alpha_{\mathrm{S} 1}$-casein or $11 \mathrm{~S}$ globulin used here were not self-associated by transglutaminase. Thus, the cross-linkages between glutamines in casein or $11 \mathrm{~S}$ globulin and amino groups in ovomucin can form in the experiment system used here. As judged by the electrophoresis in Fig. 5, the conjugates of ovomucin with casein or soy protein appear to be formed by transglutaminase. Great decreases in the staining of carbohydrate-rich component ( $\beta$-ovomucin) were observed in the carbohydrate-staining patterns of electrophoresis, compared with the pattern of self-associated ovomucin (Fig. 1). In addition, considerable increases in the sharp band in stacking gel were observed in the carbohydrate-staining patterns of electrophoresis in the conjugates. These results suggest that heterogeneous conjugates are formed between ovomucin and casein or soy protein. This was further confirmed by measuring the molecular weight of the conjugates, as shown in Fig. 6.

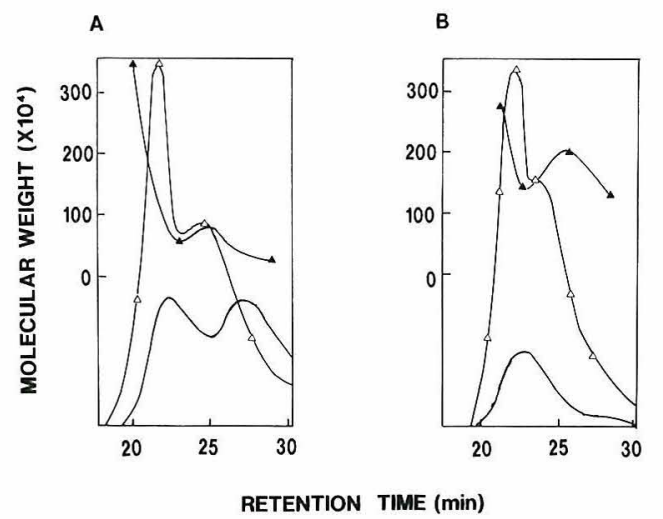

Fig. 6. Elution Patterns of Ovomucin- $\alpha_{\mathrm{S}_{1}}$-Casein and Ovomucin-11S Globulin Conjugates on a TSK Gel G3000SW Column Obtained with a Low-angle Laser Light Scattering Photometer $(-\triangle-)$ and Precision Differential Refractometer (-).

A, ovomucin- $\alpha_{\mathrm{S} 1}$-casein; B, ovomucin-11S globulin. molecular weight.

The molecular weights of ovomucin- $\alpha_{\mathrm{S} 1}$-casein conjugate and ovomucin-11S globulin conjugate were larger than that of self-associated 


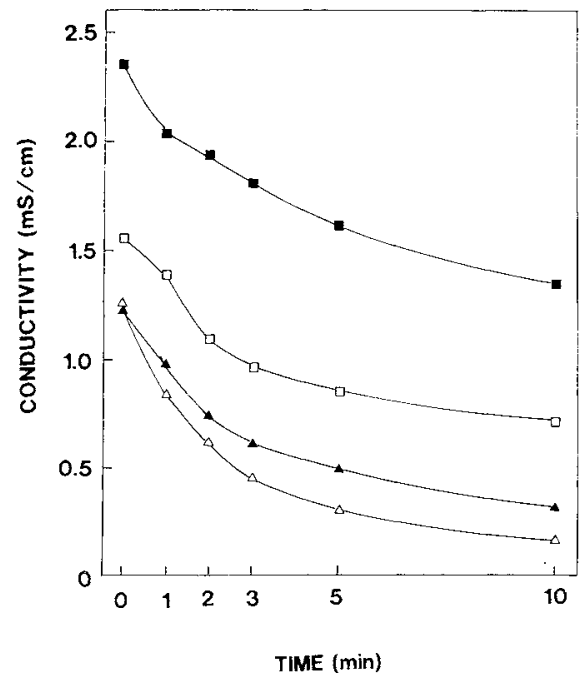

Fig. 7. Foaming Properties of Ovomucin- $\alpha_{\$ 1}$-Casein and Ovomucin-11S Globulin Conjugates.

$\triangle$, ovomucin $+\alpha_{S 1}$-casein; $\boldsymbol{\Delta}$, ovomucin $+\alpha_{S 1}$-casein + transglutaminase; $\square$, ovomucin + IIS globulin; $\mathbf{C}$, ovomucin + 11S globulin + transglutaminase.

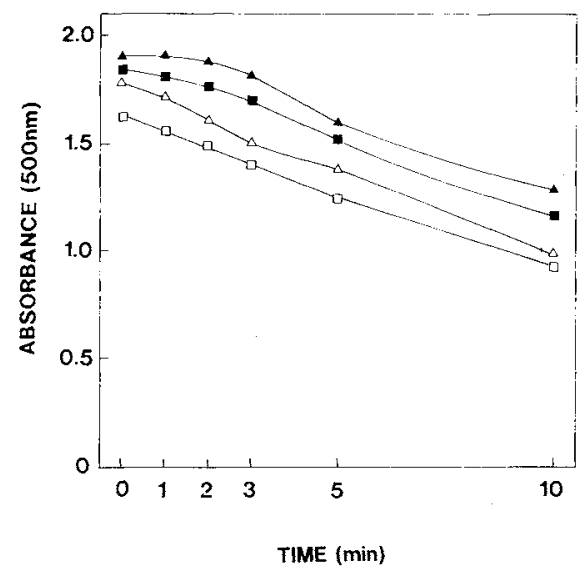

Fig. 8. Emulsifying Properties of Ovomucin- $\alpha_{\mathrm{S}_{1}}$-Casein and Ovomucin-1 IS Globulin Conjugates.

$\triangle$, ovomucin $+\alpha_{\mathrm{S} 1}$-casein; $\mathbf{\Lambda}$, ovomucin $+\alpha_{\mathrm{S} 1}$-casein + transglutaminase; $\square$, ovomucin + I IS globulin; $\mathbf{\square}$, ovomucin + IS globulin + transglutaminase.

ovomucin. In addition, the elution patterns of these conjugates were apparently different from self-associated ovomucin, suggesting the formation of heterogeneous conjugates between ovomucin and $\alpha_{\mathrm{S} 1}$-casein or $11 \mathrm{~S}$ globulin.
The foaming properties of ovomucin-11S globulin conjugate were greatly improved, reflecting the increase in the molecular weight. On the other hand, those of ovomucin- $\alpha_{\mathrm{S}_{1}}$ casein conjugate were decreased, despite the increase in the molecular weight (Fig. 7). The foaming properties of ovomucin seem to be inhibited in the presence of $\alpha_{\mathrm{S}_{1}}$-casein. This may be attributed to the low foaming properties of $\alpha_{\mathrm{S} 1}$-casein. As $\alpha_{\mathrm{S} 1}$-casein has $8 \mathrm{~mol}$ ecules of phosphate residues per mole, the formation of foam film may be disturbed by their electrostatic repulsive force.

The emulsifying properties of ovomucin- $\alpha_{\mathrm{S} 1}$ casein or ovomucin-11S globulin were greatly increased, as shown in Fig. 8. This may be due to the increase in the amphiphilic property by conjugation of ovomucin with casein or soy protein.

In conclusion, ovomucin was self-associated and conjugated with soy protein or casein by transglutaminase. The reactants had good foaming and emulsifying properties. Thus, the conjugation of ovomucin with other proteins by transglutaminase is shown to be a promising method to make new functional proteins.

\section{References}

1) A. Kato, K. Murata and K. Kobayashi, J. Agric. Food Chem., 36, 421 (1988).

2) A. Kato, Y. Sasaki, R. Furuta and K. Kobayashi, Agric. Biol. Chem., 54, 107 (1990).

3) A. Kato, R. Nakamura and Y. Sato, Agric. Biol. Chem., 34, 854 (1970)

4) C. A. Zittle and J. H. Custer, J. Dairy Sci., 46, 1183 (1963).

5) V. H. Thanh, K. Okubo and K. Shibasaki, Plant Physiol., 56, 19 (1975).

6) U. K. Laemmli, Nature, 227, 680 (1970).

7) T. Takagi and S. Hizukuri, J. Biochem., 95, 1459 (1984).

8) K. N. Pearce and J. E. Kinsella, J. Agric. Food Chem., 26, 716 (1978).

9) A. Kato, A. Takahashi, N. Matsudomi and K. Kobayashi, J. Food Sci., 48, 62 (1983).

10) S. B. Yan and F. Wold, Biochemistry, 23, 3759 (1984).

11) S. Hayakawa and Y. Sato, Agric. Biol. Chem., 40, 2397 (1976). 